\title{
Gusher: An Unpredictable Challenge in Stapedectomy
}

\author{
Nair NP*, Patro SK, Rizwi K, Goyal A, Rajan N and Verma AK \\ ${ }^{1}$ Department of Otorhinolaryngology, All India Institutes of Medical Sciences, India \\ ${ }^{2}$ Department of Radiodiagnosis, All India Institutes of Medical Sciences, India
}

*Corresponding author: Nithin Prakasan Nair, Senior Resident, Department of

\section{Case Report}

Volume 4 Issue 2

Received Date: August 09, 2019

Published Date: August 27, 2019

DOI: $10.23880 /$ ooaj-16000184

Otorhinolaryngology, AIIMS Jodhpur, India, Tel: 9443384751; Email: nithinprakasannair.2008@gmail.com

\section{Abstract}

Introduction: Stapedectomy is a routine procedure done for otosclerosis. Generally imaging is not done as a part of workup. Peri lymphatic gusher is one of the rare intraoperative complication seen during the procedure.

Case Report: Here we are reporting a 19-year-old boy who was diagnosed to have left ear otosclerosis, underwent stapedectomy under local anaesthesia. He had intra operative peri lymphatic gusher which was managed intra operatively. During post-operative period, imaging was done and patient was found to have enlarged vestibular aquaduct of left side.

Discussion: This is one of the rarest complications of the procedure. Such complications may be predicted preoperatively by a preoperative HRCT temporal bone. HRCT temporal bone should be considered during the routine workup of patients with conductive hearing loss.

Keywords: Stapedectomy, Otosclerosis, Peri lymphatic gusher, Rinne test

\section{Introduction}

Stapedectomy is a surgical procedure done for otosclerosis. Gusher is a rare complication which occurs during Stapedectomy in which there may be a sudden exit of peri lymphatic fluid [1]. In a study conducted by Ginsberg, et al. they found that $0.5 \%$ of their surgical cases had this complication [2]. It may be sometimes associated with X- linked syndrome. Imaging is not done routinely as a part of workup of such cases. Here we report a case of gusher, which was managed intraoperatively and was found to be associated due to enlarged vestibular aquaduct.

\section{Case Report}

19-year-old male patient presenting with gradually progressive insidious onset hearing loss in left ear since childhood. He had history of single episode of ear discharge in childhood. There was no history of vertigo or tinnitus or aural fullness. There was no family history of hearing loss. Clinical examination revealed normal tympanic membrane on both side ears. Tuning fork assessment was suggestive of mixed hearing loss over left side, with weber lateralised to left ear. Rinnes were positive for $256 \mathrm{~Hz}, 512 \mathrm{~Hz}$ and $1024 \mathrm{~Hz}$ on right side. Rinne test were negative for $256 \mathrm{~Hz}$ and $512 \mathrm{~Hz}$ and positive for $1024 \mathrm{~Hz}$. Weber was lateralised to left. Absolute bone conduction was reduced on left side and same on right side as compared to examiner. Pure tone audiogram was suggestive of mixed hearing over left ear with $\mathrm{AB}$ gap of $40 \mathrm{~dB}$.(AC/BC:62/22dB).

On left ear exploratory tympanotomy, Stapes fixation was confirmed and controlled fenestration of stapes was done. As soon as controlled fenestration was done, pulsating clear fluid gush was seen. Primary management was done gelfoam and temporalis fascia graft closure, 


\section{Otolaryngology Open Access Journal}

followed by insertion of Teflon piston. We planned for a reverse Stapedectomy, hence stapes suprastructure was not removed during the procedure. But post operatively patient had severe vertigo with tinnitus and no improvement in hearing. On post op day 5, revision exploratory tympanotomy was done and fenestra site was inspected. Stapes suprastructure with footplate was removed. Temporalis fascia along with tissue glue was applied to seal the site and Teflon piston was inserted and crimped to incus. Post operatively, patient did not have any complaints of vertigo, but had complaints of tinnitus and hearing loss persistent hearing loss.

During post-operative period, HRCT temporal bone was done. Oblique reformation of the image was done. In the image we can see left side enlarged vestibular aqueduct with a diameter measuring $3.3 \mathrm{~mm}$ at opercular level and $2.5 \mathrm{~mm}$ at mid-point. This could have been the cause of perilymphatic gusher (Figure 1). Patient is on regular post-operative follow-up and is found to have no improvement in hearing. On 6 months follow up, tunning fork test was suggestive of left side mixed hearing loss. Rinne test were negative for $256 \mathrm{~Hz}$ and $516 \mathrm{~Hz}$. Rinnes was positive for $1024 \mathrm{~Hz}$. Weber was lateralised to left and absolute bone conduction was reduced over left side as compared to examiner. Pure tone audiogram was too suggestive of mixed hearing loss over left ear with similar AB Gap (AC/BC: 68/24dB).

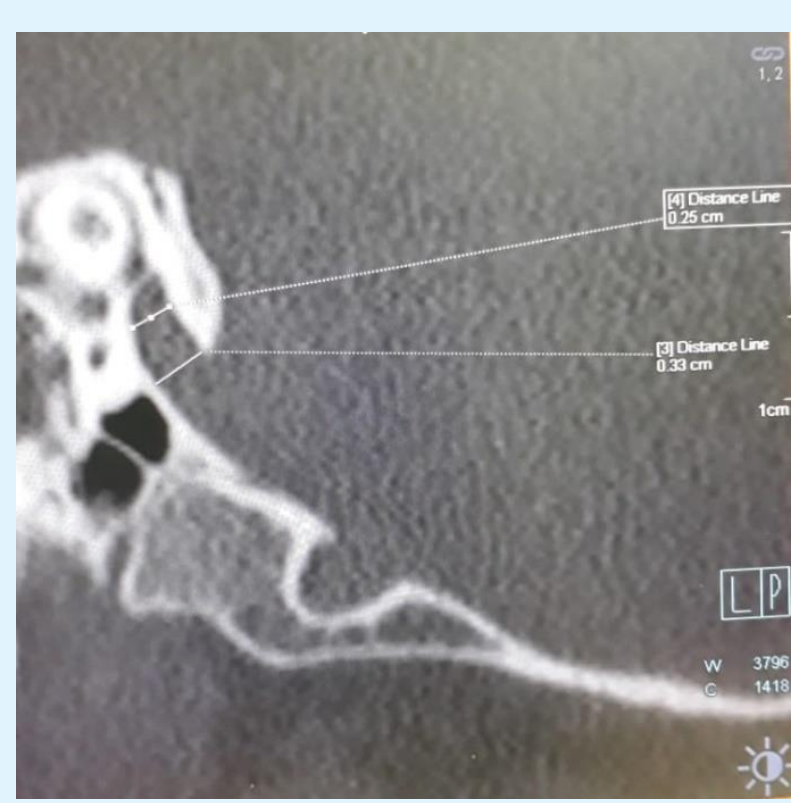

Figure 1: Showing oblique reformation of axial images of left side temporal bone with enlarged vestibular aquaduct.

\section{Discussion}

Peri lymphatic gusher is a dreaded complication during stapedectomy. Incidence of peri lymphatic gusher is found to be $0.5 \%$ [2]. There is X Linked deafness disease association. In our case there was an enlarged vestibular aquaduct on left side, which was found post operatively. Even though in some places HRCT temporal bone is done routinely as a part of work up of patients with conductive hearing loss, it is not routinely done in our part of the country. Routine HRCT temporal bone may not diagnose such findings. Oblique reformation of the images may be required to identify such findings. Diameter more than $2 \mathrm{~mm}$ at operculam and more than $1 \mathrm{~mm}$ at midpoint is considered to be an enlarged vestibular aquaduct as per Cinncinatti criteria, meanwhile, a diameter more than $1.5 \mathrm{~mm}$ is considered to be enlarged vestibular aquaduct as per Valvassori criteria [3]. As per both criteris its evident that in our case the vestibular duct on left side is enlarged.

There are very few retrospective analyses, as such scenario are rare. When we go back through literature, what we can notice is that such patients who are been operated, end up with profound hearing loss or persist with preoperative hearing. Eventhough the study conducted by Krouchi, et al. had all patients with preoperative imaging, still they were not able to identify the risk of peri lymphatic gusher. But on reviewing the CTs after surgery, they could appreciate the enlarged vestibular aquaduct [4]. A retrospective analysis of 38 patients revealed that a watershed closure of ooze should be done intraoperatively [5]. Another retrospective analysis showed that there is no improvement in hearing post operatively managing such cases [4]. A large duration multicentric prospective study will be needed for establishing the evidence for HRCT temporal bone and to assess the post-operative results in such scenarios.

\section{Conclusion}

A pre-operative HRCT temporal bone may suggest any risk of peri lymphatic gusher with an oblique reformation may help to such intraoperative catastrophise.

\section{References}

1. Cassano P, Decandia N, Cassano M, Fiorella ML, Ettorre G (2003) Perilymphatic gusher in stapedectomy: demonstration of a fistula of internal auditory canal. Acta Otorhinolaryngol Ital 23(2): 116119. 


\section{Otolaryngology Open Access Journal}

2. Ginsberg IA, Hoffman SR, Stinziano GD, White TP (1978) Stapedectomy--in depth analysis of 2405 cases. Laryngoscope 88(12): 1999-2016.

3. Connor SEJ, Dudau C, Pai I, Gaganasiou M (2019) Is CT or MRI the optimal imaging investigation for the diagnosis of large vestibular aqueduct syndrome and large endolymphatic sac anomaly? Eur Arch Otorhinolaryngol 276(3): 693-702.

4. Krouchi L, Callonnec F, Bouchetemblé P, Tollard E, Dehesdin D, et al. (2013) Preoperative computed tomography scan may fail to predict perilymphatic gusher. Ann Otol Rhinol Laryngol 122(6): 374-377.

5. Quesada JL, Cammaroto G, Bonanno L, Galletti F, Quesada P (2017) Cerebrospinal fluid leak during stapes surgery: Gushing leaks and oozing leaks, two different phenomena. Ear Nose Throat J 96(8): 302310. 